\title{
Bilateral Optic Nerve Edema in Central-variant Posterior Reversible Encephalopathy Syndrome
}

\author{
Hideki Doi, Hiroaki Yokote, Toshiki Uchihara and Shuta Toru
}

Key words: posterior encephalopathy syndrome, optic nerve edema, central-variant PRES, MRI, visual disturbance

(Intern Med 59: 2333-2334, 2020)

(DOI: 10.2169/internalmedicine.4919-20)
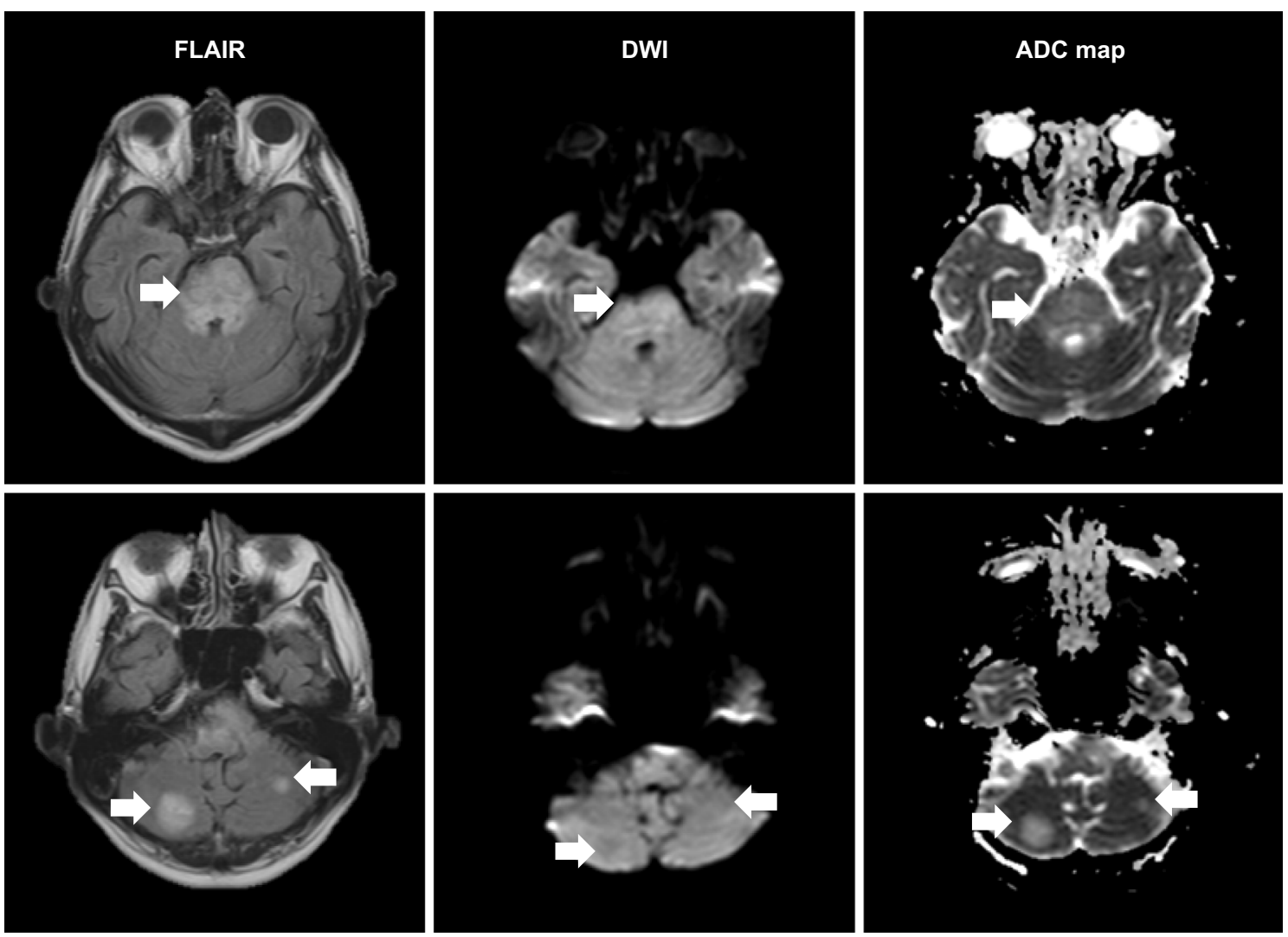

Picture 1.

A 73-year-old man with subacute hydronephrosis due to metastasis of the colorectal cancer presented with suddenonset visual disturbance. An examination revealed macular edema and hypertensive retinopathy with severe hypertension. The visual acuity was at the 'counting fingers' level. Brain magnetic resonance imaging showed diffuse T2prolonged lesions in the brainstem and spotty lesions in the cerebellum, with elevated apparent diffusion coefficient val- ues (Picture 1). In addition, short $\mathrm{T} 1$ inversion recovery images revealed hyperintensity in the optic nerves (Picture 2). After continuous administration of nicardipine under the diagnosis of central-variant posterior reversible encephalopathy syndrome (PRES), the visual acuity as well as the imaging abnormalities were rapidly improved (Picture 3), suggesting that vasogenic edema had been present not only in the brainstem and cerebellum but also in the optic nerves. Al- 

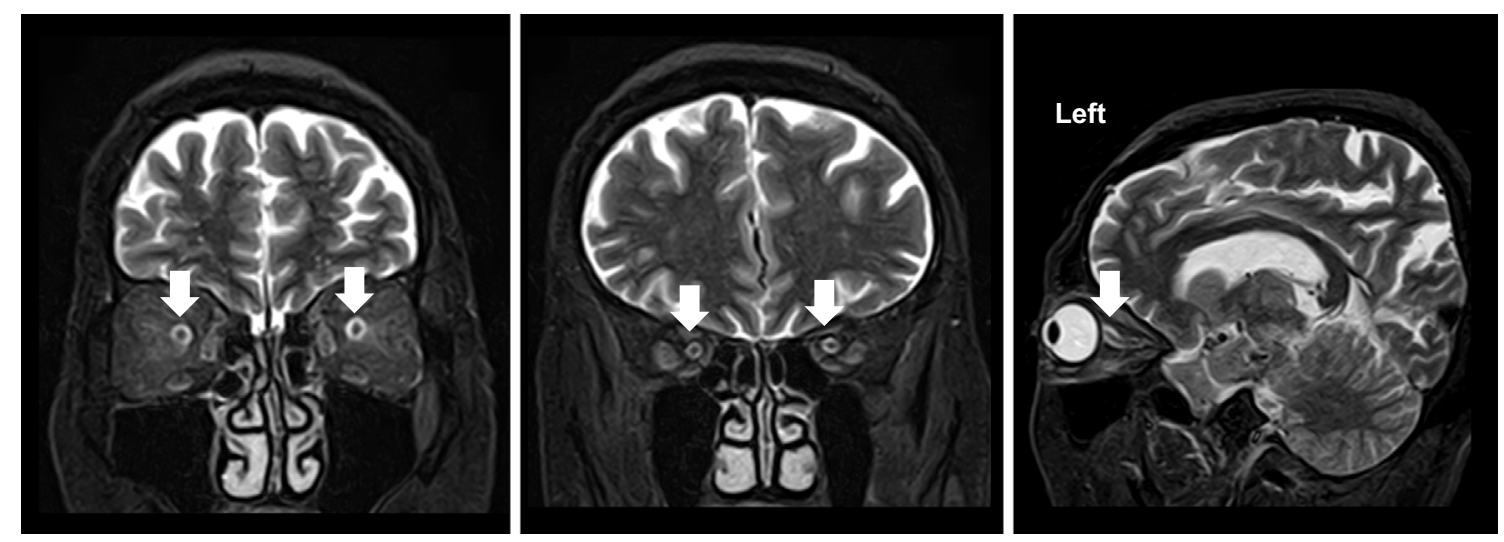

Picture 2.
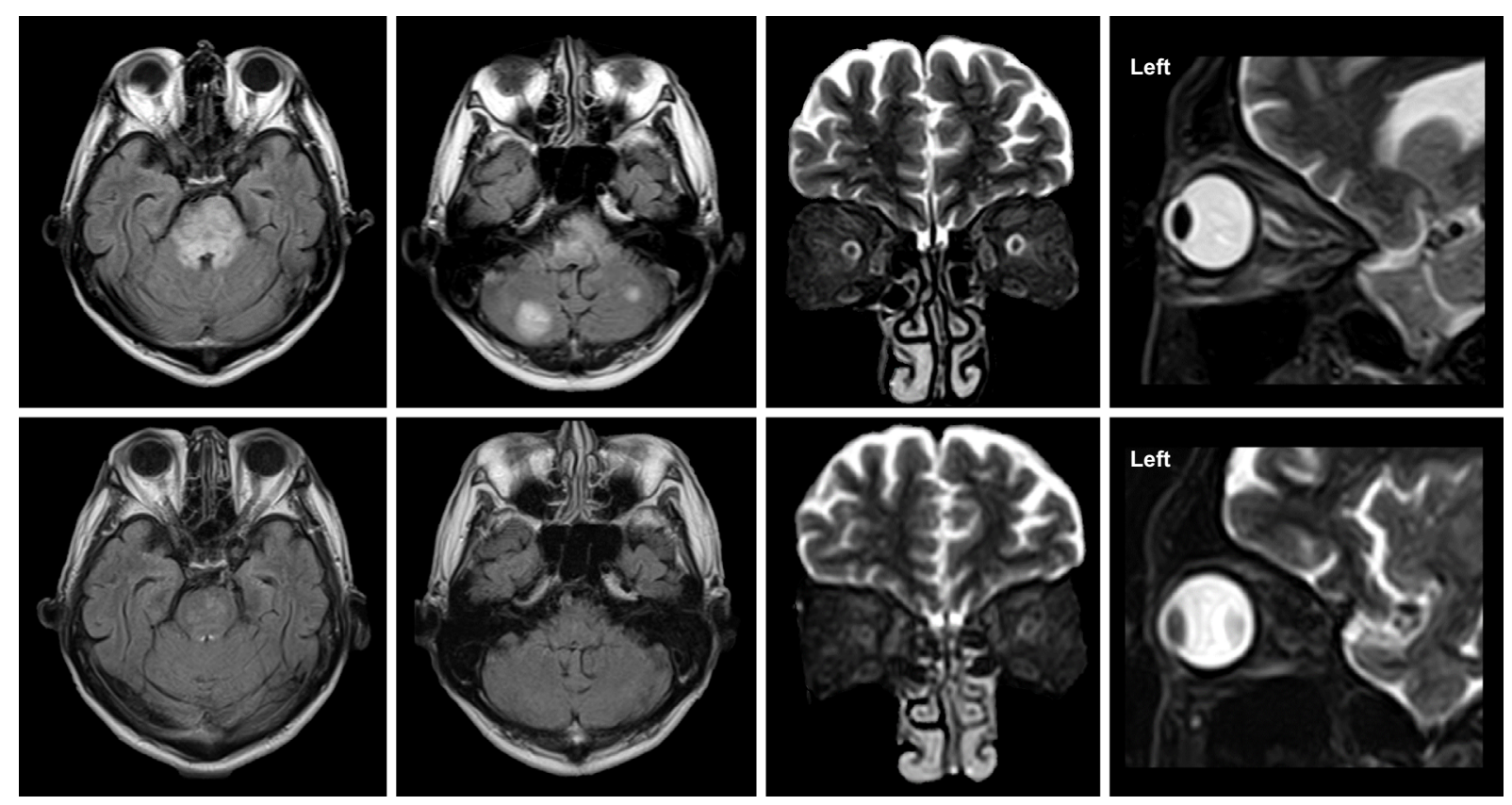

Picture 3.

though optic nerve involvement in patients with PRES has only been rarely reported $(1,2)$, patients with central-variant PRES can have optic nerve edema that may be associated with severe visual disturbance.

The authors state that they have no Conflict of Interest (COI).

\section{References}

1. Fugate J, Rabinstein A. Posterior reversible encephalopathy syn- drome: clinical and radiological manifestations, pathophysiology, and outstanding questions. Lancet Neurol 14: 914-295, 2015.

2. Cruz-Flores S, Gondim F, Leira C. Brainstem involvement in hypertensive encephalopathy: clinical and radiological findings. Neurology 62: 1417-1419, 2004.

The Internal Medicine is an Open Access journal distributed under the Creative Commons Attribution-NonCommercial-NoDerivatives 4.0 International License. To view the details of this license, please visit (https://creativecommons.org/licenses/ by-nc-nd/4.0/).

(C) 2020 The Japanese Society of Internal Medicine

Intern Med 59: 2333-2334, 2020 